\title{
Adjunctive Dexmedetomidine Infusion in Open Living Donor Hepatectomy: A Way to Enhance Postoperative Analgesia and Recovery
}

\author{
Wei-Cheng Tseng ${ }^{1}$, Wei-Lin Lin $^{1}$, Hou-Chuan Lai ${ }^{1}$, Teng-Wei Chen ${ }^{1}$, Yu-Chen Chiu ${ }^{1}$, \\ Pin-Hsuan $\mathrm{Chen}^{1}$, and Zhi-Fu $\mathrm{Wu}^{2}$ \\ ${ }^{1}$ Tri-Service General Hospital \\ ${ }^{2}$ Chi Mei Medical Center
}

July 2, 2020

\begin{abstract}
Background: Open living donor hepatectomy $(\mathrm{OLDH})$ is a highly painful procedure. Advanced strategies for enhancing perioperative analgesia and accelerating recovery are needed for patients undergoing OLDH. This study evaluated the effects of intravenous infusion of dexmedetomidine (DEX) during OLDH on postoperative analgesia and recovery. Methods: This prospective, randomized, double-blinded, and placebo-controlled study included 34 patients randomized to a control group (group C) and a DEX group (group D). Utilization of intravenous patient-controlled analgesia (IV-PCA) pump, pain intensity, and postoperative recovery variables were recorded. Moreover, intraoperative anesthetic consumption, hemodynamic parameters, and fluid status were also recorded. Results: During the first 24 hours after surgery, patients in group D had a lower pain intensity. The cumulative numbers of IV-PCA pump presses and fentanyl consumption within 24 and 48 hours postoperatively in group $\mathrm{C}$ were significantly higher than in group D. The time to first IV-PCA attempt was prolonged in group D. In addition, faster flatus passage was observed in group D. Intraoperatively, fewer anesthetic agents were required in group D. Less fluctuation in hemodynamics and reduced bleeding were also found in group D. Conclusions: The present study revealed that the addition of intravenous infusion of DEX during OLDH provided several benefits in relieving postoperative pain and promoting recovery. Therefore, we concluded that intraoperative DEX infusion may play an important role in enhancing recovery of patients undergoing OLDH.
\end{abstract}

\section{Hosted file}

Cover letter.doc available at https://authorea.com/users/339050/articles/465343adjunctive-dexmedetomidine-infusion-in-open-living-donor-hepatectomy-a-way-to-enhancepostoperative-analgesia-and-recovery

\section{Hosted file}

Title page.docx available at https://authorea.com/users/339050/articles/465343adjunctive-dexmedetomidine-infusion-in-open-living-donor-hepatectomy-a-way-to-enhancepostoperative-analgesia-and-recovery

\section{Hosted file}

Manuscript.docx available at https://authorea.com/users/339050/articles/465343adjunctive-dexmedetomidine-infusion-in-open-living-donor-hepatectomy-a-way-to-enhancepostoperative-analgesia-and-recovery 

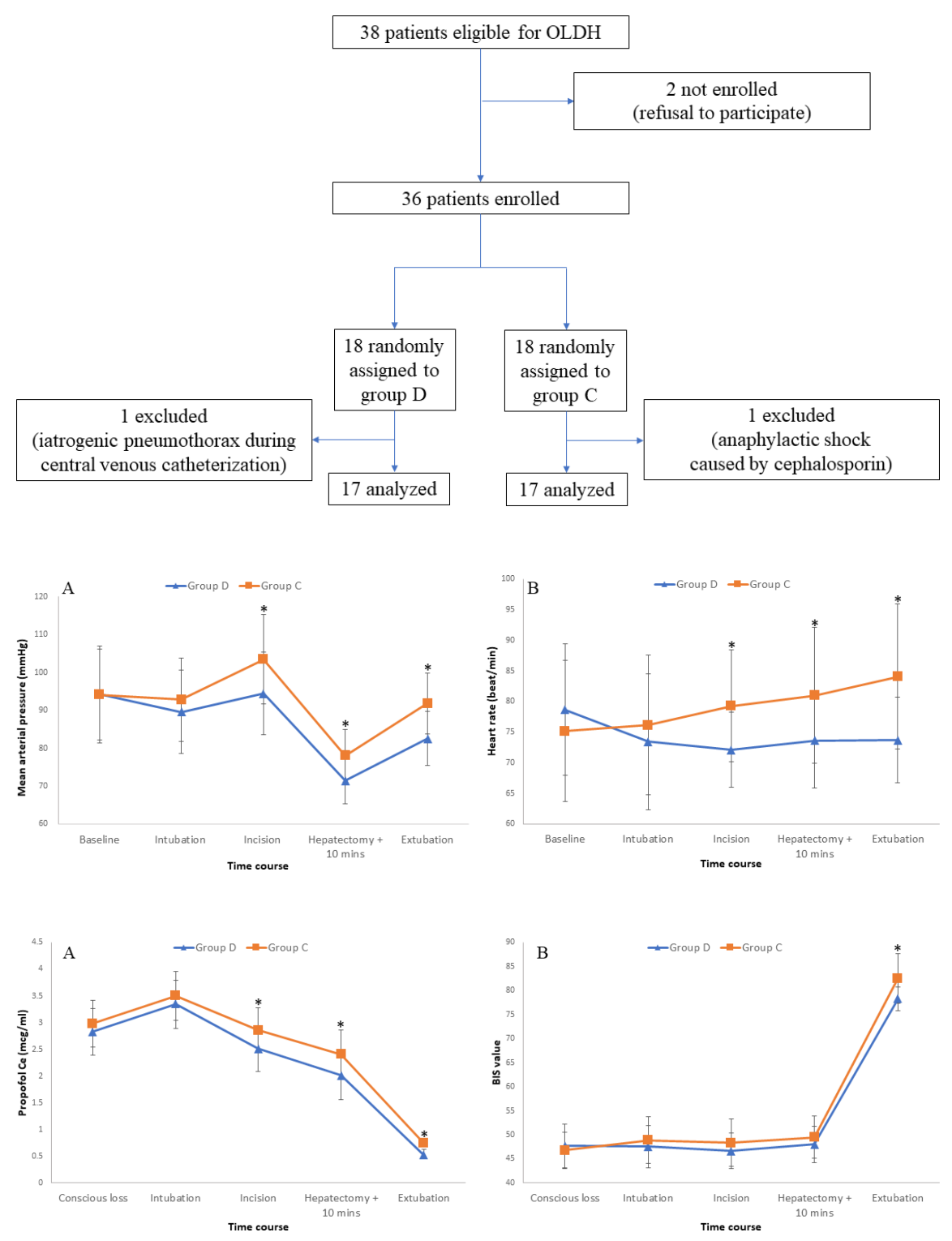